\title{
Dominant influenza $\mathrm{A}(\mathrm{H} 3 \mathrm{~N} 2)$ and $\mathrm{B} /$ Yamagata virus circulation in EU/EEA, 2016/17 and 2017/18 seasons, respectively
}

Cornelia Adlhoch ${ }^{1}$, René Snacken ${ }^{1}$, Angeliki Melidou ${ }^{2}$, Silviu Ionescu ${ }^{1}$, Pasi Penttinen ${ }^{1}$, the European Influenza Surveillance Network ${ }^{3}$

1. European Centre for Disease Prevention and Control (ECDC), Stockholm, Sweden

2. Microbiology Department, School of Medicine, Aristotle University of Thessaloniki, Thessaloniki, Greece

3. The members of the European Influenza Surveillance Network are listed at the end of article

Correspondence: Cornelia Adlhoch (Cornelia.Adlhoch@ecdc.europa.eu)

Adlhoch Cornelia, Snacken René, Melidou Angeliki, lonescu Silviu, Penttinen Pasi, the European Influenza Surveillance Network. Dominant influenza A(HzN2) and B/Yamagata virus circulation in EU/EEA, 2016/17 and 2017/18 seasons, respectively. Euro Surveill. 2018;23(13):pii=18-00146. https://doi.org/10.2807/1560-7917. ES.2018.23.13.18-00146

We use surveillance data to describe influenza $A$ and $B$ virus circulation over two consecutive seasons with excess all-cause mortality in Europe, especially in people aged 60 years and older. Influenza $A\left(\mathrm{H}_{3} \mathrm{~N}_{2}\right)$ virus dominated in 2016/17 and B/Yamagata in 2017/18. The latter season was prolonged with positivity rates above $50 \%$ among sentinel detections for at least 12 weeks. With a current west-east geographical spread, high influenza activity might still be expected in eastern Europe.

The yearly influenza epidemics during each winter season vary in burden and severity. During the 2016/17 and 2017/18 seasons, all-cause excess mortality was observed during periods of high influenza virus circulation $[1,2]$. Our aim is to describe and compare the pattern of influenza virus circulation and related disease severity by number of patients and fatal cases in intensive care units (ICUs) across European Union/ European Economic Area (EU/EEA) countries for the seasons 2016/17 and 2017/18. As influenza circulation progressed from a west to east direction across Europe in $2017 / 18$, a better understanding of the current epidemiological situation might help to prepare countries in the eastern part of the World Health Organization (WHO) European Region for high influenza activity and severity [3].

\section{Influenza surveillance in Europe}

The European Influenza Surveillance Network (EISN) performs influenza surveillance from week 40 to week 20 of the following year $[4,5]$. Weekly epidemiological and virological influenza data are collected from 30 EU/EAA countries and 11 countries report data on severe and fatal cases with laboratory-confirmed influenza in ICUs. Collected data in selected primary care settings include the percentage of these sentinel specimens testing positive for influenza [6].

\section{Influenza virus circulation in the $2016 / 17$} and $2017 / 18$ seasons

The influenza virus positivity rates among sentinel specimens in EU/EEA countries over the 2016/17 and 2017/18 seasons are shown in Figure 1.

\section{6/17 seasonal influenza epidemic}

Sentinel surveillance outcome

The 2016/17 epidemic was characterised by an early start, with overall sentinel detections crossing the $10 \%$ positivity threshold in week 46/2016 (Figure 1) and with a dominance $(75 \% ; 10,242 / 13,584)$ of influenza $\mathrm{A}\left(\mathrm{H}_{3} \mathrm{~N}_{2}\right)$ viruses among all positive sentinel specimens, $17 \%(n=2,318)$ influenza A unsubtyped, $1 \%(n=172)$ $A\left(H_{1} N_{1}\right) p d m o 9,2 \%(n=281) B$ no lineage, $1 \%(n=117)$ B/Victoria and 3\% ( $n=454)$ B/Yamagata lineage) [7]. Only Slovenia reported a substantial proportion (44\%; $113 / 259)$ of $B /$ Yamagata viruses in sentinel specimens (Figure 2). The positivity rate in the EU/EEA remained above $10 \%$ for 27 consecutive weeks with a dominance of B/Yamagata viruses in the final weeks of the season. The peak phase with positivity levels above 50\% (maximum positivity: $57 \%$ ) lasted for 6 consecutive weeks.

Results from surveillance in intensive care units

During 2016/17, 10 countries (Czech Republic, Denmark, Finland, France, Ireland, Romania, Slovakia, Spain, Sweden, and the United Kingdom (UK)) reported a total of 3,959 patients admitted to ICUs with laboratory-confirmed influenza (Figure 3). Of these patients, $96 \%(\mathrm{n}=3,813)$ were infected with influenza A virus, with $92 \%(1,465 / 1,592)$ of the subtyped $A$ viruses being 


\section{FIGURE 1}

Percentage positivity for influenza viruses among sentinel specimens, by week and season, European Union/European Economic Area, 2016/17 and 2017/18 (up to week 11)

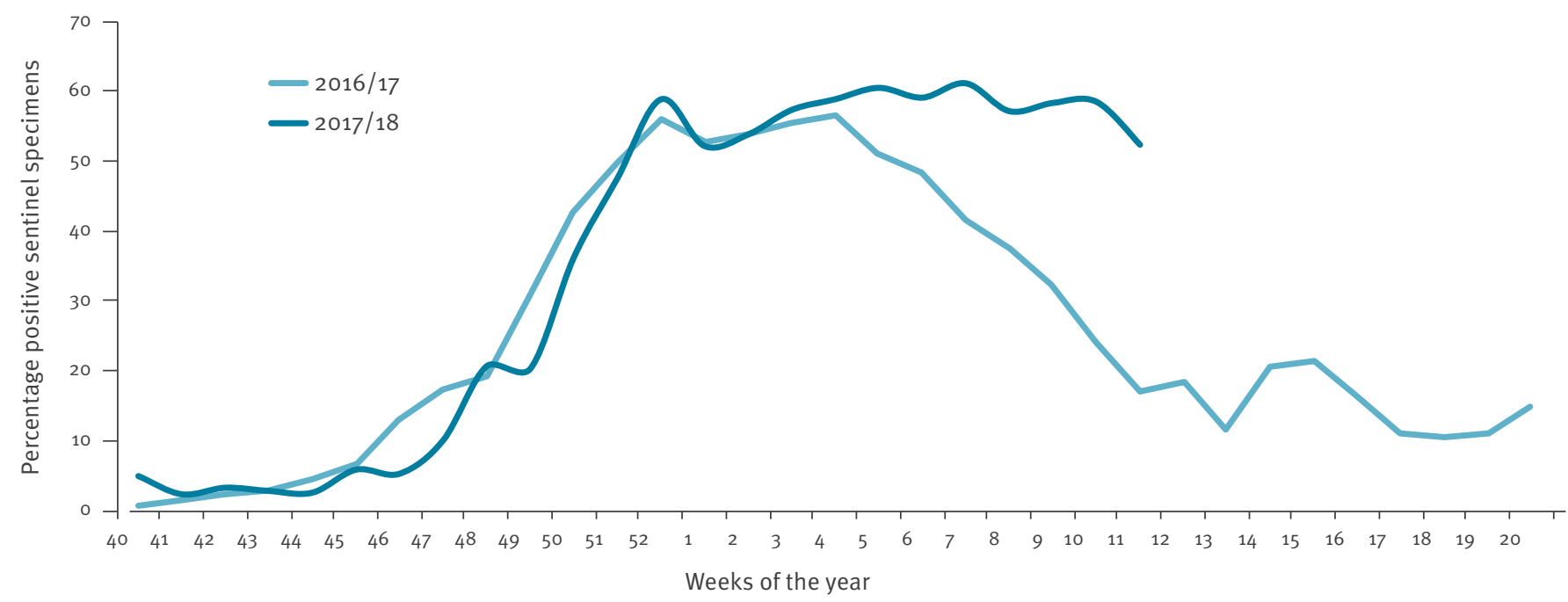

\section{FIGURE 2}

Distribution of viral types/subtypes in sentinel specimens by country, European Union/European Economic Area, influenza season 2016/17

Influenza viruses circulating in $2016 / 17^{\mathrm{a}}$
Subtype $\mathrm{A}\left(\mathrm{H}_{1}\right) \%$
Subtype $A\left(\mathrm{H}_{3}\right) \%$
Type A unsubtyped \%
Type B \%
EU/EEA countries
Other countries
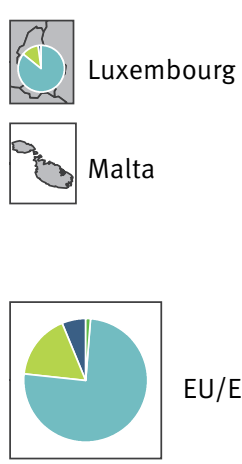

EU/EEA
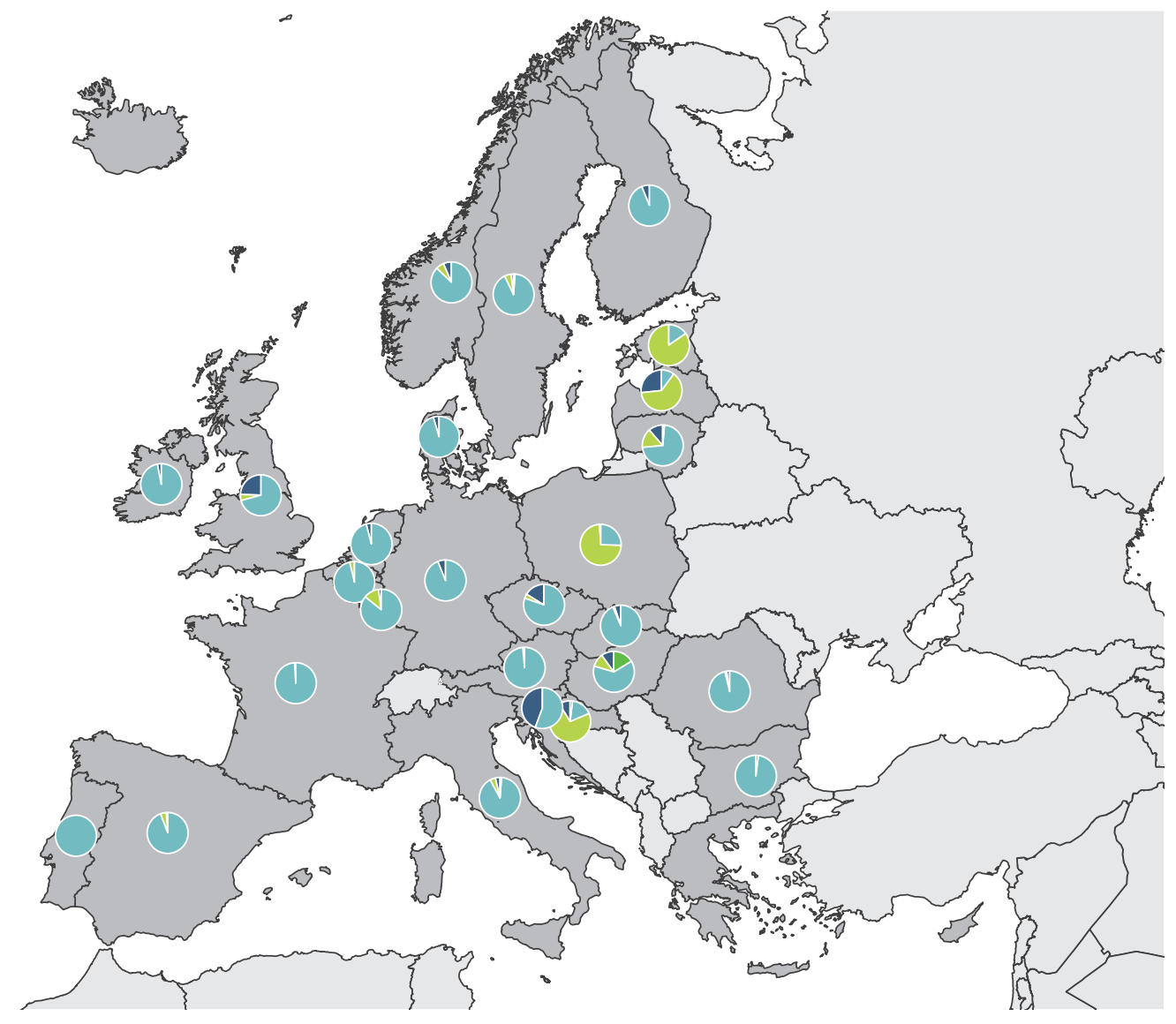

EU/EEA: European Union/European Economic Area.

a Only sentinel specimens are included. 


\section{FIGURE 3}

Distribution of laboratory-confirmed influenza cases admitted to ICU, by age group and type/subtype, in the reporting European Union/European Economic Area countries, 2016/17 season ( $\mathrm{n}=2,827$ patients) ${ }^{\mathrm{a}}$

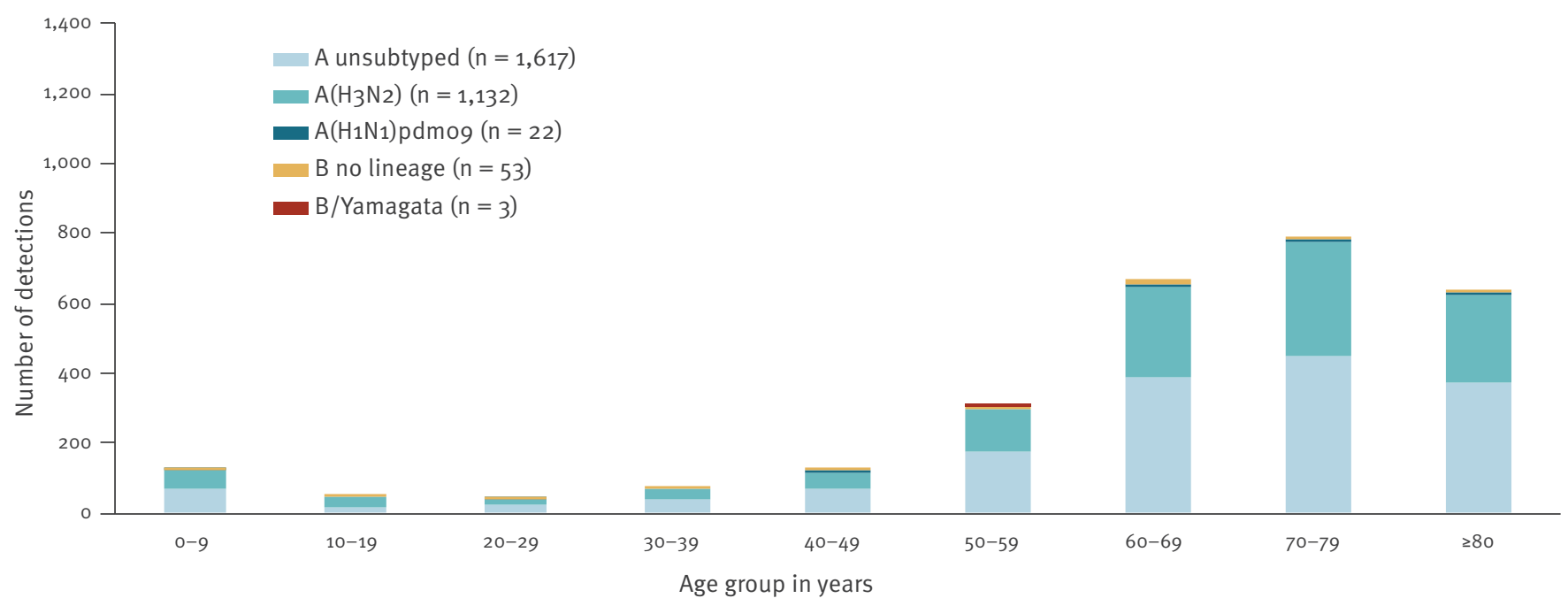

ICU: intensive care unit.

a Of the total reported 3,959 patients, 2,827 where age information was available are included in the figure.

\section{FIGURE 4}

Distribution of viral types/subtypes in sentinel specimens by country, European Union/European Economic Area, influenza season 2017/18 (up to week 11)

Influenza viruses circulating in $2017 / 18^{\mathrm{a}}$

\section{Subtype $A\left(\mathrm{H}_{1}\right) \%$}

Subtype $A\left(\mathrm{H}_{3}\right) \%$

Type A unsubtyped \%

Type B \%

EU/EEA countries

Other countries
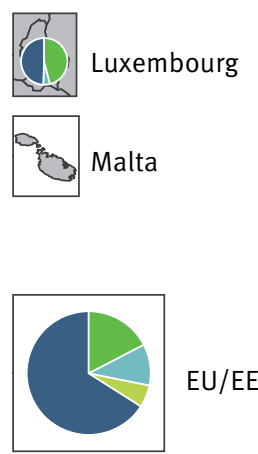

Euter

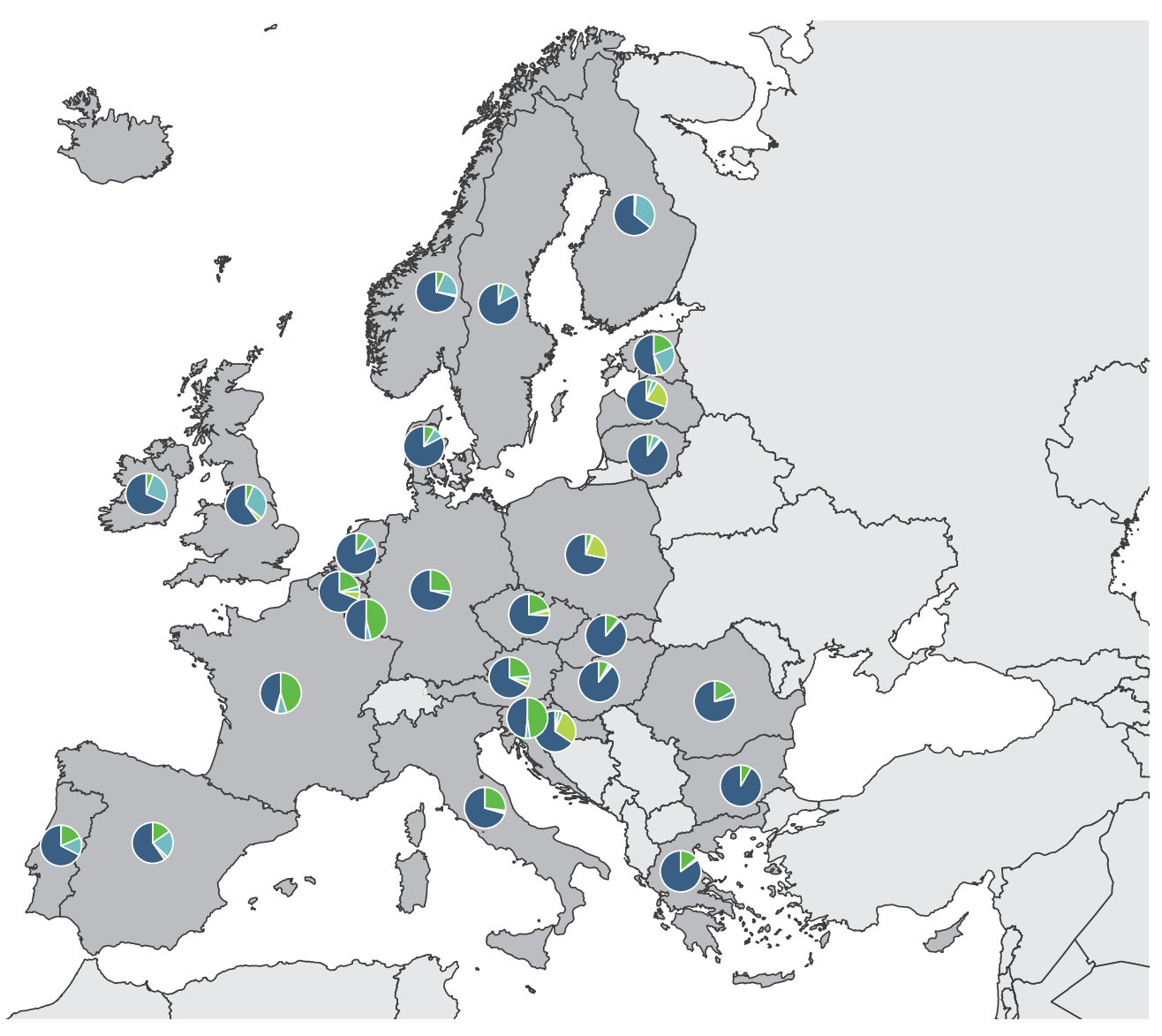

EU/EEA: European Union/European Economic Area.

a Only sentinel specimens are included. 
Distribution of laboratory-confirmed influenza cases admitted to ICU, by age group and type/subtype, in the reporting European Union/European Economic Area countries, 2017/18 season (up to week 11) $(\mathrm{n}=4,754)^{\mathrm{a}}$

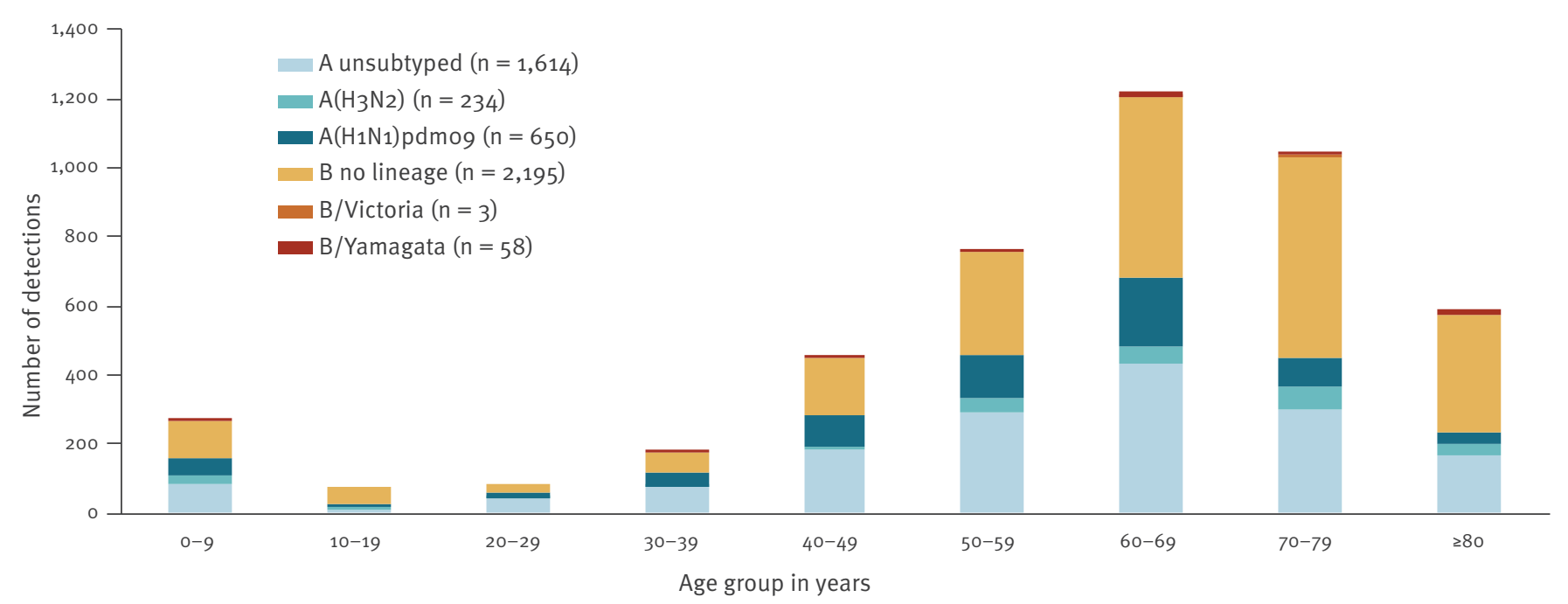

a Of the total reported 7,789 patients, 4,754 where age information was available are included in the figure.

$\mathrm{A}\left(\mathrm{H}_{3} \mathrm{~N}_{2}\right)$. The majority of cases $(81 \% ; 3,194 / 3,959)$ were reported from three countries, namely France ( $n=1,469$ cases), the UK $(n=1,109)$ and Spain $(n=616)$. Most cases in the $2016 / 17$ season occurred up to week 11 , by which $97 \%(3,837 / 3,959)$ of all the season's cases in ICU and 99\% (593/599) of all fatal cases had been reported.

\section{7/18 seasonal influenza epidemic}

Sentinel surveillance outcome

During the $2017 / 18$ season, the influenza positivity of tested sentinel specimens passed the $10 \%$ threshold in week 47 2017, and the 50\% threshold in week 522017 . Positivity rates exceeded $52 \%$ for over 12 weeks indicating an unusually protracted peak period of influenza activity across the countries (maximum positivity: $61 \%$; Figure 1). In the previous seven seasons, the number of weeks with a positivity of $50 \%$ and higher ranged between o (2009/10; 2013/14) and 8 (2012/13; 2015/16) weeks.

During the initial weeks of the $2017 / 18$ season, similar numbers of influenza $A$ and $B$ viruses were detected in sentinel specimens, but between weeks 482017 and 112018 , influenza $B$ viruses were dominant (66\%; $12,455 / 18,888)$. Among $B$ viruses with lineage determination, $97 \%(5,687 / 5,860)$ were of the Yamagata lineage. Overall during this period, $6 \%(n=1,102)$ unsubtyped influenza $A, 17 \%(n=3,283) A\left(\mathrm{H}_{1} \mathrm{~N}_{1}\right)$ pdmo9, $11 \%(n=2,048) A\left(H_{3} N_{2}\right), 35 \%(n=6,595)$ $B$ without lineage determination, $1 \%(n=173) B /$ Victoria and $30 \%(n=5,687) B /$ Yamagata lineage were detected. All countries had a proportion of sentinel B viruses of $46 \%$ or higher. Both influenza $A\left(\mathrm{H}_{1} \mathrm{~N}_{1}\right)$ pdmog and $A\left(H_{3} \mathrm{~N}_{2}\right)$ viruses co-circulated with $B$ viruses, but the pattern and magnitude varied across countries. These different patterns are more visible at countrylevel (Figure 4).

\section{Results from surveillance in intensive care units}

Up to week 11 2018, 7,789 laboratory-confirmed influenza cases in ICUs were reported from 10 countries (Czech Republic, Denmark, Finland, France, Ireland, the Netherlands, Romania, Spain, Sweden, and the UK). Altogether, the UK $(n=2,983)$, France $(n=2,614)$ and Spain $(n=1,119)$ reported the vast majority of cases $(86 \% ; 6,716 / 7,789)$. Comparing data up to week 11 in $2017 / 18$ to the complete $2016 / 17$ season, this is an increase of ICU cases by $169 \%, 78 \%$ and $82 \%$ in these countries, respectively (Figure 3, Figure 5).

Influenza A was detected in $52 \%(\mathrm{n}=4,036)$ of the 7,789 patients, and $59 \%(n=872)$ of the 1,471 subtyped influenza $A$ viruses were reported as $A\left(\mathrm{H}_{1} \mathrm{~N}_{1}\right)$ pdmog with $51 \%(n=449)$ of them reported by France. The vast majority $(81 \% ; 190 / 234)$ of all $B$ viruses as well as $\mathrm{A}\left(\mathrm{H}_{3} \mathrm{~N}_{2}\right)$ viruses were detected in ICU patients aged 50 years and older. The majority $(64 \%$; 419/650) of patients infected with $\mathrm{A}\left(\mathrm{H}_{1} \mathrm{~N}_{1}\right)$ pdmog were 40 to 69 years-old.

\section{Disease severity in 2016/17 and 2017/18}

The severity of disease caused by $B$ viruses during the $2017 / 18$ season is also reflected in the high proportion of $B$ infections among fatal outcomes reported from ICUs $(49 \%$; $420 / 851)$. This is in contrast with the previous season in which $1 \%(5 / 599)$ of fatal cases in ICUs died of influenza B infection. In 2016/17, 0.5\% (3/599) of the fatal cases were infected with $\mathrm{A}\left(\mathrm{H}_{1} \mathrm{~N}_{1}\right)$ pdmog, $44 \%(266 / 599)$ with $\mathrm{A}\left(\mathrm{H}_{3} \mathrm{~N}_{2}\right)$ and $54 \%$ (325/599) with 
an unsubtyped influenza A virus. In 2017/18, $15 \%$ (124/851) of the fatal cases were infected with $A\left(\mathrm{H}_{1} \mathrm{~N}_{1}\right)$ pdmog, $5 \%(42 / 851)$ with $\mathrm{A}\left(\mathrm{H}_{3} \mathrm{~N}_{2}\right)$ and $31 \%(265 / 851)$ with an unsubtyped influenza $A$ virus.

Among all cases reported with influenza B infection in ICUs and known outcome, 5/52 (10\%) died in 2016/17, while $420 / 1,983(21 \%)$ died in $2017 / 18$. More than $50 \%$ $(333 / 636)$ of all fatal cases over 60 years of age had influenza $B$ and among fatal cases infected with influenza B virus, $79 \%$ (333/420) were 60 years of age and older. A similar distribution between virus type and age has been also observed in the B/Yamagata virus dominated season 2012/13.

\section{Discussion}

The ongoing 2017/18 influenza season with dominant circulation of influenza $B$ and a co-circulation of $\mathrm{A}\left(\mathrm{H}_{1} \mathrm{~N}_{1}\right)$ pdmog and/or $\mathrm{A}\left(\mathrm{H}_{3} \mathrm{~N}_{2}\right)$ viruses is proving to have a severe impact, as did the $2016 / 17$ season with its dominance of influenza $A\left(\mathrm{H}_{3} \mathrm{~N}_{2}\right)$. The dominance of $A\left(\mathrm{H}_{3} \mathrm{~N}_{2}\right)$ viruses associated with a high severity, prolonged season and all-cause excess mortality in the EU/EEA in 2016/17 [2] is comparable to the situation in the United States during the $2017 / 18$ season [8]. The dominant B/Yamagata virus circulation with mixed $A$ virus pattern in 2017/18 causing high severity, long duration of peak influenza activity and all-cause excess mortality in the EU/EEA is comparable to $2012 / 13$, an influenza $\mathrm{B} /$ Yamagata virus dominated season with $A\left(\mathrm{H}_{1} \mathrm{~N}_{1}\right)$ pdmo9 and $\mathrm{A}\left(\mathrm{H}_{3} \mathrm{~N}_{2}\right)$ co-circulation $[1,2,9,10]$. Influenza $\mathrm{A}\left(\mathrm{H}_{3} \mathrm{~N}_{2}\right)$ viruses are known to affect disproportionately those aged above 65 years, leading to outbreaks in long-term care homes, increases in hospitalisation and mortality in this age group [11,12]. B viruses are described as causing milder disease and affecting more the younger age groups [13]. In both seasons described here, however, we observed the highest number of severe cases in patients admitted to ICUs aged 60 years and older. As seen previously, patients infected with $\mathrm{A}\left(\mathrm{H}_{1} \mathrm{~N}_{1}\right)$ pdmog in ICU were slightly younger than patients infected with influenza $A\left(\mathrm{H}_{3} \mathrm{~N}_{2}\right)$ or $B[14,15]$.

The reason for the prolonged and increased activity as well as the severe clinical impact of influenza $B$ viruses during the $2017 / 18$ season is not fully understood. Countries perform either sentinel or universal hospital surveillance and no major change in reporting has occurred which would explain the increase of cases in ICU [16].

Although the most commonly used trivalent vaccine contained the B/Victoria lineage in both 2016/17 and 2017/18 seasons, a moderate vaccine effectiveness for $\mathrm{B} /$ Yamagata and $\mathrm{A}\left(\mathrm{H}_{1} \mathrm{~N}_{1}\right)$ pdmog in $2017 / 18$ was observed; the effectiveness for $A\left(\mathrm{H}_{3} \mathrm{~N}_{2}\right)$ viruses in both seasons, however, was low $[12,17]$. The moderate and low vaccine effectiveness as well as low vaccine coverage might have contributed to the lower protection in the population together with an accumulation of susceptible people since the last dominant B/Yamagata circulation five seasons ago [18]. Further in-depth analyses are needed to describe the mostly affected population and identify relevant underlying co-morbidities and other factors, e.g. cold weather, that might have contributed to the prolonged virus activity and severity. Neuraminidase inhibitors remain an option for the prophylaxis and treatment of the currently circulating influenza viruses, and their use should be considered along the national and international guidance and recommendations, especially for cases with severe and rapidly progressing disease [19]. The season in Europe has progressed in a marked west-east direction and countries in the eastern part of the WHO European Region should be prepared for possible cases of severe disease and impact on healthcare services. However, influenza activity remains high also in central and western parts of Europe with continuously observed all-cause mortality.

Members of the European Influenza Surveillance Network

WHO: Piers Mook, Tamara Meerhoff; Austria: Theresia Popow-Kraupp, Daniela Schmid; Belgium: Barbezange Cyril, Bossuyt Nathalie, Moreels Sarah, Thomas Isabelle, Van Casteren Viviane; Bulgaria: Korsun Neli; Croatia: Draženović Vladimir; Cyprus: Koliou Maria, Pieridou Despo; Czech Republic: Havlíčková Martina, Jiřincová Helena, Kynčl Jan, Denmark: Fischer Thea Kølsen, Krause Knudsen Lisbet, Trebbien Ramona; Estonia: Päll Kaie, Sadikova Olga; Finland: Haveri Anu, Ikonen Niina, Lyytikäinen Outi, Murtopuro Satu; France: Behillil Sylvie, Bernard-Stoecklin Sibylle, Blanchon Thierry, Campese Christine, Enouf Vincent, Lina Bruno, Turbelin Clement, Valette Martine, van der Werf Sylvie; Germany: Buda Silke, Dürrwald Ralf; Greece: Kalkouni Ourania, , Mentis Andreas, Papa Anna, Pogka Vasiliki; Hungary: Jankovics István, Molnár Zsuzsanna, Rózsa Mónika; Iceland: Löve Arthur, Sigmundsdóttir Guðrún; Ireland: Connell Jeff, Domegan Lisa, Duffy Margaret, Dunford Linda, O’Donnell Joan; Italy: Bella Antonino, Rizzo Caterina, Simona Puzelli, Maria Rita Castrucci; Latvia: Nikiforova Raina, Pakarna Gatis, Zamjatina Natalija; Liechtenstein: Jamnicki Abegg Marina; Lithuania: Griškevičius Algirdas, Lipnickienè Vilnelè, Muralytè Svajūnė; Luxembourg: Fournier Guillaume, Nguyen Trung; Malta: Barbara Christopher, Maistre Melillo Jackie, Melillo Tanya, Zahra Graziella; The Netherlands: de Lange Marit, Dijkstra Frederika, Donker Ge, Fouchier Ron, Hooiveld Mariette, Marbus Sierk, Meijer Adam, Teirlinck Anne; Norway: Bragstad Karoline, Dudman Susanne Gjeruldsen, Hauge Siri Helene, Hungnes Olav, Tønnessen Ragnhild; Poland: Brydak Lidia, Cieślak Katarzyna, Zielinski Andrzej; Portugal: Figueiredo Augusto Gonçalo, Machado Jorge, Moreira Guiomar Raquel, Nogueira Paulo, Rebelo De Andrade Helena, Rodrigues Ana Paula; Romania: Ivanciuc Alina, Odette Popovici, Popescu Rodica; Slovakia: Staronová Edita, Mikas Ján; Slovenia: Berginc Nataša, Prosenc Katarina, Sočan Maja, Grilc Eva; Spain: Casas Inmaculada, Delgado Sanz Concha, Larrauri Amparo, Marcos María Angeles, Oliva Jesus, Ortiz De Lejarazu Leonardo Raul, Pozo Francisco, Vega Tomas; Sweden: Mia Brytting, AnnaSara Carnahan; United Kingdom: Coyle Peter, Daniels Rodney Stuart, Gunson Rory, Kearns Cathriona, MacLean Alasdair, McCaughey Conall, McMenamin Jim, Moore Catherine, Nugent Christopher, Pebody Richard, Phin Nick, Potts Alison, Reynolds Arlene, Shaw Primrose Louise, Zambon Maria. 


\section{Acknowledgement}

We thank the influenza surveillance team at World Health Organization Regional Office for Europe, Copenhagen, Demark, for their collaboration.

We thank all EISN members and ERLI-Net laboratories for their tireless commitment in collecting and providing highquality European influenza surveillance data.

We are also grateful to the TESSy data managers for their support and ECDC staff for their critical review.

\section{Conflict of interest}

None declared.

\section{Authors' contributions}

CA: concept, data analysis and manuscript draft; RS: data analysis, manuscript review; AM: data and manuscript review; SI: figure development, data analysis and manuscript approval; PP: data analysis and manuscript review; members of the network provided data, reviewed the analysis and approved the manuscript.

\section{References}

1. European monitoring of excess mortality for public health action - EuroMOMO. Copenhagen: EuroMOMO. [Accessed 23 Mar 2018]. Available from: http://www.euromomo.eu/index. htm

2. Vestergaard LS, Nielsen J, Krause TG, Espenhain L, Tersago $\mathrm{K}$, Bustos Sierra N, et al. Excess all-cause and influenzaattributable mortality in Europe, December 2016 to February 2017. Euro Surveill. 2017;22(14):30506. https://doi. org/10.2807/1560-7917.ES.2017.22.14.30506 PMID: 28424146

3. European Centre for Disease Prevention and Control (ECDC) and World Health Organization (WHO) Regional Office for Europe. Flu News Europe - Joint ECDC-WHO/Europe weekly influenza update, Archives season 2017-18. Week 11/2018 (12-18 March 2018). ECDC/WHO. Available from: http://flunewseurope.org/ Archives

4. Paget J, Marquet R, Meijer A, van der Velden K. Influenza activity in Europe during eight seasons (1999-2007): an evaluation of the indicators used to measure activity and an assessment of the timing, length and course of peak activity (spread) across Europe. BMC Infect Dis. 2007;7(1):141. https:// doi.org/10.1186/1471-2334-7-141 PMID: 18047685

5. Meijer A, Valette M, Manuguerra JC, Pérez-Breña P, Paget J, Brown C, et al. Implementation of the community network of reference laboratories for human influenza in Europe. J Clin Virol. 2005;34(2):87-96. https://doi.org/10.1016/j. jCv.2005.02.005 PMID: 16157259

6. Meijer A, Brown C, Hungnes O, Schweiger B, Valette M, van der Werf S, et al. Programme of the Community Network of Reference Laboratories for Human Influenza to improve Influenza Surveillance in Europe. Vaccine. 2006;24(4446):6717-23. https://doi.org/10.1016/j.vaccine.2006.05.068 PMID: 16782242

7. European Centre for Disease prevention and Control (ECDC). Risk assessment update: seasonal influenza, EU/ EEA, 2016-2017. Stockholm: ECDC; 25 Jan 2017. Available from: https://ecdc.europa.eu/en/publications-data/ risk-assessment-update-seasonal-influenza-eueea-2016-2017

8. Budd AP, Wentworth DE, Blanton L, Elal AIA, Alabi N, Barnes J, et al. Update: Influenza Activity - United States, October 1, 2017-February 3, 2018. MMWR Morb Mortal Wkly Rep. 2018;67(6):169-79. https://doi.org/10.15585/mmwr.mm6706a1 PMID: 29447145

9. Adlhoch C, Broberg E, Beauté J, Snacken R, Bancroft E, Zucs P, et al. Influenza season $2013 / 14$ has started in Europe with influenza $A\left(\mathrm{H}_{1}\right)$ pdmog virus being the most prevalent subtype. Euro Surveill. 2014;19(4):20686. https://doi. org/10.2807/1560-7917.ES2014.19.4.20686 PMID: 24507465
10. European monitoring of excess mortality for public health action - EuroMoMo. Pooled analyses of all-cause mortality indicates low excess mortality in Europe in the winter of 2013/14, in particular amongst the elderly. 2014. Copenhagen: EuroMOMO. [Accessed 23 Mar 2018]. Available from: http:// www.euromomo.eu/methods/pdf/pooled_analyses winter 2013 14.pdf

11. Beauté J, Broberg E, Plata F, Bonmarin I, O Donnell J, Delgado $C$, et al. Overrepresentation of influenza $A\left(\mathrm{H}_{1} \mathrm{~N}_{1}\right)$ pdmog virus among severe influenza cases in the $2011 / 12$ season in four European countries. Euro Surveill. 2012;17(9):20105. PMID: 22401564

12. Pebody R, Warburton F, Ellis J, Andrews N, Potts A, Cottrell $S$, et al. End-of-season influenza vaccine effectiveness in adults and children, United Kingdom, 2016/17. Euro Surveill. 2017;22(44):17-00306. https://doi.org/10.2807/1560-7917. ES.2017.22.44.17-00306 PMID: 29113630

13. Tran D, Vaudry W, Moore D, Bettinger JA, Halperin SA, Scheifele DW, et al. Hospitalization for Influenza A Versus B. Pediatrics. 2016;138(3):e20154643. https://doi.org/10.1542/peds.20154643 PMID: 27535144

14. Snacken R, Quinten C, Devaux I, Plata F, Broberg E, Zucs P, et al. Surveillance of hospitalised severe cases of influenza $\mathrm{A}\left(\mathrm{H}_{1} \mathrm{~N}_{1}\right)$ pdmog and related fatalities in nine EU countries in 2010-2011. Influenza Other Respi Viruses. 2012;6(6):e936. https://doi.org/10.1111/j.1750-2659.2012.00406.x PMID: 22788875

15. Karageorgopoulos DE, Vouloumanou EK, Korbila IP, Kapaskelis A, Falagas ME. Age distribution of cases of $2009\left(\mathrm{H}_{1} \mathrm{~N}_{1}\right)$ pandemic influenza in comparison with seasonal influenza. PLoS One. 2011;6(7):e21690. https://doi.org/10.1371/journal. pone.0021690 PMID: 21747947

16. World Health Organization (WHO) Regional Office for Europe. Influenza surveillance country profiles of WHO European Region Member States 2017. Copenhagen: WHO. [Accessed 12 Feb 2018]. Available from: http://www.euro.who.int/en/ health-topics/communicable-diseases/influenza/surveillanceand-lab-network/influenza-surveillance-country-profiles/ influenza-surveillance-country-profiles-of-who-europeanregion-member-states

17. Rondy M, Kissling E, Emborg H-D, Gherasim A, Pebody $\mathrm{R}$, Trebbien R, et al. Interim 2017/18 influenza seasonal vaccine effectiveness: combined results from five European studies. Euro Surveill. 2018;23(9):18-00086. https://doi. org/10.2807/1560-7917.ES.2018.23.9.18-00086 PMID: 29510782

18. European Centre for Disease Prevention and Control (ECDC). Seasonal influenza vaccination in Europe; Vaccination recommendations and coverage rates in the EU Member States for eight influenza seasons, 2007-2008 to 2014-2015 Stockholm: ECDC; 2017. Available from: https://ecdc.europa. eu/en/publications-data/seasonal-influenza-vaccinationeurope-vaccination-recommendations-and-coverage-2007-2015

19. European Centre for Disease Prevention and Control (ECDC). Expert Opinion on neuraminidase inhibitors for prevention and treatment of influenza - review of recent systematic reviews and meta-analyses. Stockholm: ECDC; 2017. Available from: https://ecdc.europa.eu/sites/portal/files/documents/ Scientific-advice-neuraminidase-inhibitors-2017.pdf

\section{License and copyright}

This is an open-access article distributed under the terms of the Creative Commons Attribution (CC BY 4.0) Licence. You may share and adapt the material, but must give appropriate credit to the source, provide a link to the licence, and indicate if changes were made.

This article is copyright of the authors, 2018. 